\title{
Avaliação Sob Risco da Capacidade de Pagamento por Água Bruta de Produtores da Bacia do Jaguaribe (CE)
}

Robério Telmo Campos ${ }^{1}$

Resumo: Este estudo avalia a capacidade de pagamento, sob condições de risco, dos produtores rurais usuários de água bruta da bacia do Jaguaribe, no estado do Ceará. Levam-se em conta o sistema de irrigação - se privado ou público, o perímetro, o nível de consumo e as atividades produzidas. Os dados são de natureza primária, obtidos por meio da aplicação de 93 questionários junto a irrigantes privados e públicos. Como método de análise, usa-se a técnica de simulação Monte Carlo. Conclui-se que, para os irrigantes privados e públicos da amostra, a capacidade de pagamento (CP) por água bruta apresenta valor médio negativo e que a maioria desses produtores não tem condição de pagar pelo uso da água, representando risco elevado às atividades desenvolvidas. Somente os irrigantes que registraram renda líquida (residual ou net-back), sob condições deterministas, maior que zero podem pagar o valor da tarifa atualmente cobrada pela Companhia de Gestão dos Recursos Hídricos (Cogerh) com sobra de caixa ou baixo risco. Alguns irrigantes não têm possibilidade alguma de arcar com a tarifa atual. Os irrigantes públicos apresentaram maior $\mathrm{CP}$ comparados aos privados. A atividade pecuária foi a que registrou menor risco para arcar com a tarifa.

Palavras-chave: capacidade de pagamento, irrigantes, risco, água bruta.

Abstract: This paper aims to evaluate the capacity of payment, under risk conditions, of the bulk water to the rural producers' users in Jaguaribe basin, State of Ceará. It was considered the aspects concerning whether the irrigation system is public or private, the location of the irrigation district, the level of consumption level and the activities being carried out. The data are primary, gathered by the application of 93 questionnaires to producers in private and public irrigation districts. As method of analysis, it is used the Monte Carlo simulation. We can conclude that for the sample of public and private irrigation farmers, the capacity of payment (CP) for bulk water shows a negative average value and that the majority of

1 E-mail: roberio@ufc.br 
these producers cannot afford to pay for the water use, which represents high risk for the activities carried out. Only the irrigation farmers that showed net income (residual or netback), under deterministic conditions, higher than zero, can pay with large margin or low risk the value of tariff being charged currently by the water governmental agency (Cogerh). Some irrigation farmers do not show any probability of paying the current tariff. The public irrigation farmers show higher $\mathrm{CP}$ relatively the private ones. The cattle-raising activity was the one that showed lower risk concerning the tariff charged.

Key-words: capacity of payment, irrigation stakeholders, risk, bulk water.

Classificação JEL: M11, Q15, Q25.

\section{Introdução}

Embora três quartos da superfície da Terra sejam cobertos por água, o equivalente a 1,5 bilhão de quilômetros cúbicos $\left(\mathrm{km}^{3}\right)$, somente $1 \%$ está disponível para o consumo humano (água doce) - 97\% do total constitui-se de água salgada e $2 \%$ compõem as geleiras polares.

Entre as explicações está o crescimento acelerado da demanda por água doce nas últimas décadas, a taxas nunca vistas na história. $\mathrm{O}$ consumo doméstico aumentou mais de 35 vezes nos três últimos séculos e quadruplicou em 50 anos (CAMPOS e STUDART, 2001). No estado do Ceará, em particular, onde o semiárido responde por $92 \%$ da área total, o setor agrícola absorve $60 \%$ dos recursos hídricos para irrigação, sendo alvo constante de adversidades e políticas restritivas em decorrência da falta d'água.

Assim, ao contrário da demanda, a oferta de água para uso agrícola, humano e animal decresce a cada ano, seja em função da degradação ambiental seja por desperdícios e poluição (contaminação), que conduzem ao esgotamento em certas áreas ou à deterioração da qualidade das reservas atualmente disponíveis.

O modelo prevalecente até hoje no Ceará é o de administrar a oferta de água por meio de açudes. Nos últimos cem anos, foram construídos mais de 8.000 reservatórios. Somente públicos são 136 açudes, com capacidade de armazenar 17,9 bilhões de metros cúbicos $\left(\mathrm{m}^{3}\right)$ de água. Apesar de todo investimento, as pessoas têm feito uso da água de forma cada vez mais ineficiente. No setor de irrigação, a eficiência dificilmente atinge $30 \%$. Em áreas urbanas os níveis de perdas chegam a $60 \%$. Enquanto isso, as tarifas cobradas pela água de irrigação têm sido muito baixas ou de valor zero (KEMPER e OLSON, 1998).

Nesse contexto, mesmo com uma grande quantidade de reservatórios, o estado do Ceará atravessa crises constantes de suprimento de água, tanto para irrigação como para consumo humano. Dados do Anuário de Monitoramento Quantitativo dos Principais Açudes do Estado do Ceará, divulgado pela Companhia de Gestão dos Recursos Hídricos (Cogerh), indicam que o volume 
de água necessário para atender os perímetros situados no Alto, Médio e Baixo Jaguaribe chegou, em janeiro de 2003, às mínimas de 18,4\%, 48,2\% e 3\%, respectivamente, da capacidade total de cada sistema.

Essa situação, a exemplo de outras ocorridas no País, deixa claro o porquê da cobrança de água para irrigação ter sido inserida na legislação brasileira, por meio da Lei de Irrigação 6.662, de 25 de janeiro de 1979. No Ceará, desde o final dos anos 80, o governo empenha esforços na definição de uma agenda de discussão para o uso mais racional da água. Em 1992, o estado definiu a primeira lei para a administração (política) de água. Essa lei, à semelhança das mais modernas, incorporou direitos de uso, cobrança e gestão em nível de bacia.

Formuladores da política de águas entendem que a cobrança é fundamental para estabelecer a racionalidade de seu uso e conservação, viabilizar os recursos para o seu gerenciamento e, ao mesmo tempo, aumentar o rendimento das lavouras pela adoção de sistemas produtivos mais eficazes.

Nas tarifas até hoje cobradas estão embutidos elevados subsídios governamentais, o que é criticado por alguns especialistas (CLINE, 1972; ALVES, 1988; ASSIRATI, 1994). Os custos de implantação, administração, operação e manutenção dos projetos públicos de irrigação são muito altos, superiores aos padrões internacionais, exigindo-se a participação do Estado, uma vez que produtores, em geral, não estão capitalizados para assumi-los (PEREIRA NETO, 1998). Segundo o autor, sob a óptica do novo modelo de irrigação, os projetos devem seguir a lógica de mercado e da autossuficiência, não havendo necessidade de subsídios e, cabendo ao governo, cumprir apenas as suas funções básicas, como o faz para outros segmentos da agricultura.

Regra geral, a estimação da tarifa cobrada em projetos públicos de irrigação é função de duas parcelas. Uma delas, designada por $\mathrm{K}_{1}$, destina-se a remunerar os investimentos em infraestrutura de uso comum dos projetos. A outra, denominada de $\mathrm{K}_{2}$, refere-se aos custos de administração, operação e manutenção dos projetos.

Portanto, a tarifa, da forma como é calculada - nada de anormal -, considera apenas os gastos efetuados pelo poder público para chegar ao custo $/ \mathrm{m}^{3}$ de água, ou seja, atende somente o lado de quem outorga ou oferta a água para remunerar a infraestrutura disponível. Assim, faz-se necessário analisar também a capacidade de pagamento do usuário demandante de água, levando-se em conta a rentabilidade das explorações agropecuárias, sob condições de risco.

Conforme Pinheiro e Lima (2001; 2002), nos perímetros de irrigação, a falta de sinais de mercado representados pelo preço eficiente da água e o controle da quantidade consumida impedem o seu uso racional. Enquanto todos os demais recursos utilizados têm preços que se aproximam dos seus custos de oportunidade, o mesmo não acontece com a água.

A hipótese subjacente é a de que o empreendimento cujas atividades agrícolas estejam adequadamente planejadas e executadas pode pagar a tarifa justa de água sem comprometer sua viabilidade econômica. 
Daí a necessidade de estimação da capacidade de pagamento dos usuários de água bruta em projetos de irrigação, sejam privados ou públicos. A partir dessa informação, do custo $/ \mathrm{m}^{3}$, além de fatores de ordem cultural, política, social e econômica, o poder público poderá, via regulamentação ou mecanismos de mercado, disciplinar e reduzir o desperdício bem como o uso inadequado da água, em busca de ganhos de eficiência.

Vale salientar que a cobrança é condição necessária, mas não suficiente, para se chegar à eficiência, à equidade e à sustentabilidade. No caso dos perímetros de irrigação, o efeito da cobrança pode ser anulado por outros arranjos; por exemplo, se a tarifa for única para todo o projeto (bacia hidrográfica), calculada mediante rateio pelo número de irrigantes, independente do tipo de produto que exploram, ela pode exercer pouca influência no uso da água ou na escolha de culturas.

O mercado para os produtores é outro fator que pode tornar a cobrança sem efeito, quando se relaciona ao estímulo de explorar produtos de maior valor. Os obstáculos à venda determinam a escolha da lavoura/pecuária e, em muitas situações, conduzem o irrigante à produção de culturas de subsistência, por ser a opção mais segura no caso de seus produtos não serem comercializados (CAMPOS e STUDART, 2001).

No entanto, a capacidade de pagamento, assim calculada, não leva em conta o caráter aleatório das grandezas hidrológicas, tanto quanto outras variáveis agronômicas, econômicas, sociais e ambientais que fazem parte dos sistemas de recursos hídricos e com as quais interagem.

Assim, além dos problemas inerentes aos irrigantes - uso de atividades produtivas de baixo rendimento e receitas reduzidas, tecnologias inadequadas, custos relativamente elevados, imperfeições de mercado e utilização de sistemas de irrigação não poupadores de água -, existe, ainda, a dificuldade ocasionada por incertezas ou riscos da produção agrícola e do processo de gestão de água, o que resulta, muitas vezes, na incapacidade de se pagar água de irrigação.

Dessa forma, faz-se de fundamental importância estudar, avaliar, desenvolver e difundir modelos analíticos quanto à definição da probabilidade ou capacidade de pagamento do irrigante, dado o alto risco inerente às atividades agrícolas praticadas no semiárido nordestino.

Como afirma Vieira (2001, p. 132),

na área de recursos hídricos, a fortiori, a aleatoriedade dos eventos hidrológicos, a adoção de modelos imprecisos, as hipóteses simplificadoras, a relatividade dos princípios adotados e, ainda, a forte interconexão com os componentes ambientais e socioeconômicos extremamente variados, faz com que a gestão hídrica, em todas as suas funções, atividades e instrumentos, conviva com uma vasta gama de incertezas, tanto endógenas quanto exógenas aos sistemas hídricos de que se ocupa. 
Sob essa óptica, levantam-se as seguintes questões: Qual a capacidade de pagamento dos irrigantes privado e público ${ }^{2}$ que compõem a bacia do Jaguaribe (CE)? Qual a capacidade de pagamento segundo as atividades que produzem? Considerando-se a demanda atual por água e a tarifa também cobrada atualmente pela Cogerh, há capacidade de pagamento de todos os irrigantes? De quem cobrar mais ou menos pelo uso da água, ou mesmo não cobrar? A tarifa deve ser cobrada em função da área, em relação a cada perímetro ou conforme o tipo ou combinação de atividades?

Dessa forma, este trabalho visa avaliar a capacidade de pagamento, sob condições de risco, dos produtores rurais usuários de água bruta da bacia do Jaguaribe, segundo os seguintes aspectos: tipo de irrigante (privado ou público), perímetro, nível de consumo e atividades que produzem. Com base nessas informações, pretende-se subsidiar a ação do estado para melhor adequação da matriz tarifária vigente na bacia cearense.

\section{Referencial Teórico}

\subsection{Métodos de valoração da água para irrigação ${ }^{3}$}

A seleção do método para se determinar o valor econômico da água é condicionada por diversos fatores, entre eles as características do uso da água e, especialmente, a disponibilidade de informação e a capacidade de quem realiza a valoração. Em princípio, existem vários métodos para se valorar os distintos usos da água. No entanto, alguns exigem dados técnicos e econômicos raramente disponíveis ou que envolvem complexos procedimentos de modelagem econômica. Outra restrição para a aplicação de certos métodos é a necessidade de elaboração de orçamentos (custos e receitas).

2 A Lei no 6.662, de 25 de junho de 1979, que dispõe sobre a Política Nacional de Irrigação e dá outras providências, em seu Art 26, considera irrigante a pessoa física ou jurídica que se dedique, em determinado projeto de irrigação, à exploração de lote agrícola, do qual seja proprietária, promitente-compradora ou concessionária de uso. O Art $8^{\mathrm{o}}, \S 1^{\underline{0}}$ e $\S 2^{\circ}$, da mesma lei, define o que é projeto público e privado, respectivamente. Assim sendo, o irrigante público explora atividades em projeto público de irrigação, definido como aquele cuja infraestrutura de irrigação é projetada, implantada e operada, direta ou indiretamente, sob a responsabilidade do poder público. Já o irrigante privado desenvolve suas atividades agropecuárias em projeto privado de irrigação, ou seja, é aquele cuja infraestrutura de irrigação é projetada, implantada e operacionalizada por particulares, com ou sem incentivos do poder público (BRASIL, 1979).

3 Toda essa seção apresenta-se com base em Garrido et al. (2004, p. 5-10), com pequenas alterações, em que os autores fazem uma revisão resumida dos métodos de valoração da água para irrigação. 
É frequente, ainda, pesquisadores estimarem a produtividade marginal ou média da água e extrapolarem referida produtividade para o valor econômico do recurso, o que equivale a realizar dois orçamentos. Primeiro, porque a tarifa paga pela água pode não ser a volumétrica. Segundo, o custo de suprimento da água não depende da quantidade de água aplicada, suposição bastante irreal. Portanto, ao assumir a produtividade como valor da água, realiza-se uma sobrevaloração do uso do recurso (GARRIDO et al., 2004).

Existem sete grupos de métodos de valoração da água: o método residual e suas variantes, métodos baseados em funções de produção, no uso de modelagem econométrica, modelação da produção mediante programação matemática, métodos de valoração contingente, métodos dos preços hedônicos e o método do custo alternativo.

\subsubsection{Método de análise residual}

Consiste em se atribuir como valor econômico da água a diferença entre as receitas e todos os custos (inclusive as remunerações atribuídas à terra, ao empresário e ao capital) associados aos fatores de produção, excetuando-se a água. Para tanto, faz-se necessária a realização de orçamentos detalhados das atividades da empresa.

\subsubsection{Uso de funções de produção}

Baseia-se no uso de funções de produção empíricas estimadas a partir de dados de campo ou de experimentos, em que a quantidade de água aplicada nas atividades agrícolas é a variável explicativa. Multiplicando-se a função de produção obtida pelo preço do produto encontra-se uma função de receita; ao se derivar essa função pela quantidade de água utilizada, obtém-se a receita marginal, tomada como valor marginal da água.

\subsubsection{Uso de modelos econométricos}

É possível utilizar dois tipos de modelos econométricos para se estimar funções de demanda de água. Um deles consiste na estimação direta da função de demanda de água, aplicável quando se dispõem de observações reais de preço e consumo de água. Outro tipo de modelo econométrico também se aplica para estimativas que se baseiam na quantidade consumida de água de famílias relacionando-a ao preço (diferentes sistemas tarifários), à renda e a outras características das unidades domésticas.

\subsubsection{Modelação da produção mediante programação matemática}

Por meio da programação matemática é possível obter o valor marginal da água, constituindo-se no método mais adequado para se estimar funções de 
demanda de água em sistemas de produção agrícola com mais de um cultivo. Fundamenta-se, principalmente, na utilização de modelos de alocação de superfície, água e outros fatores de produção entre diversos cultivos opcionais. A exemplo do método residual, faz-se necessário o levantamento de todos os custos de produção.

\subsubsection{Métodos de valoração contingente}

Permitem estimar empiricamente funções de demanda a partir dos valores de disposição a pagar, obtidos junto aos usuários de água por meio de pesquisa direta. Para se chegar a esses valores questionam-se o interesse de se dispor de diferentes quantidades de água e os possíveis volumes a serem utilizados para vários níveis de preços.

\subsubsection{Método de preços hedônicos}

Consiste em um método de valoração indireta utilizado tradicionalmente para a valoração de bens heterogêneos, como propriedades rurais rústicas, imóveis urbanos, bens ambientais, entre outros. Embora seja um método que utilize técnicas econométricas, faz-se a opção de separá-lo por seu caráter de método de valoração indireta. Por meio dele, busca-se determinar em que medida certas características de um bem (por exemplo, a terra) - para as quais não existe um mercado específico - afetam o seu valor, derivando-se, assim, o valor de tais aspectos (nível de conservação ou de contaminação do solo, declividade, localização, tamanho, paisagem, acesso a água, entre outros).

\subsubsection{Método do custo alternativo}

É utilizado frequentemente para a valoração da água em usos não agrícolas. Isso porque permite valorar o recurso quando, por falta de dados apropriados ou por outros motivos, não é possível obter uma função de demanda da água de maneira direta por meio dos outros métodos (GARRIDO et al., 2004).

O princípio em que tal método se baseia é que o valor da água é dado pelo custo em que se tem de incorrer, pública ou privadamente, para obter o recurso mediante a alternativa disponível de menor custo. Ou seja, o valor que se toma é o valor de oportunidade da água, entendendo como tal o da atividade produtiva que utilize a água da forma menos rentável. Para isso, é necessário se estabelecer os valores dos usos do recurso em todas as opções possíveis, por meio dos métodos descritos anteriormente. Uma das mais recentes aplicações do método do custo alternativo, objetivando determinar funções de valor marginal da água, é o trabalho de Arrojo Agudo et al. (2002). 
Avaliação Sob Risco da Capacidade de Pagamento por Água Bruta de Produtores da Bacia do Jaguaribe (CE)

\subsection{O Método de Monte Carlo}

As análises de rentabilidade costumam ser feitas sob pressuposições deterministas, em lugar de serem abordadas como modelos probabilísticos, sendo, assim, desprezadas as incertezas presentes no mundo real. Esse tipo de procedimento considera as variáveis como parâmetros conhecidos e constantes, quando, na verdade, se tratam de variáveis aleatórias, sujeitas a determinados graus de risco e incertezas (ambientais ou econômicos). O resultado, portanto, são informações incompletas para o tomador de decisão.

Dados esses fatores, o presente trabalho contemplará uma análise mais realista, isto é, em vez de considerar pressuposições simplistas dos modelos deterministas, levará em conta o aspecto aleatório das variáveis envolvidas e, consequentemente, o risco ambiental ou econômico associado à atividade produtiva. Dessa forma, os indicadores de rentabilidade não são apresentados como um valor pontual, mas como distribuições cumulativas de probabilidade.

Conceitualmente, o modelo probabilístico a ser adotado neste estudo, a exemplo de Biserra (1991) e Campos (1991), será definido por:

$$
\mathrm{r}_{\mathrm{j}}^{\mathrm{d}}=\mathrm{f}\left(\mathrm{p}^{\mathrm{d}}, \mathrm{w}_{\mathrm{z}}^{\mathrm{d}}, \mathrm{p}_{\mathrm{r}}^{\mathrm{d}}, \mathrm{s}_{\mathrm{z}}^{\mathrm{d}}, \mathrm{v}\right)
$$

em que:

$\mathrm{r}_{\mathrm{j}}^{\mathrm{d}}=$ distribuição cumulativa da probabilidade do j-ésimo indicador de rentabilidade;

$\mathrm{p}^{\mathrm{d}}=$ distribuição de probabilidade do preço real do produto produzido pela empresa;

$\mathrm{W}_{\mathrm{z}}{ }^{\mathrm{d}}=$ distribuição de probabilidade do preço real do z-ésimo insumo utilizado no processo produtivo;

$\mathrm{p}_{\mathrm{r}}{ }^{\mathrm{d}}=$ distribuição de probabilidade da produção;

$\mathrm{s}_{\mathrm{z}}{ }^{\mathrm{d}}=$ distribuição de probabilidade da quantidade do z-ésimo insumo utilizado no processo produtivo; $\mathrm{e}$

$\mathrm{v}=$ vetor de parâmetros ou "variáveis" deterministas da função.

\section{Metodologia}

\section{1. Área de estudo ${ }^{4}$}

A bacia do Jaguaribe (CE) drena uma área de $72.043 \mathrm{~km}^{2}$, correspondente a $48 \%$ do estado. $\mathrm{O}$ rio Jaguaribe percorre um trajeto aproximado de $610 \mathrm{~km}$ desde as suas nascentes até sua foz. No total, a bacia do Jaguaribe compreende 56 municípios.

4 Para detalhes sobre caracterização da área do estudo, ver Secretaria dos Recursos Hídricos do Estado do Ceará (2002). 
Pela sua dimensão, a bacia hidrográfica do Jaguaribe foi subdividida, dentro do Plano Estadual dos Recursos Hídricos, em cinco regiões hidrográficas: Alto Jaguaribe, Médio Jaguaribe, Baixo Jaguaribe, Salgado e Banabuiú.

A precipitação anual na bacia do Jaguaribe apresenta uma distribuição espacial bastante irregular, oscilando entre 500 e 1.000 milímetros (mm). A área onde são registrados os menores volumes - inferiores a $500 \mathrm{~mm}$ ao ano - compreende o setor oeste, envolvendo o Sertão dos Inhamuns. As maiores precipitações, por sua vez, ocorrem na região do Cariri, norte da bacia e Serra do Pereiro.

A irrigação representa o principal fator de demanda por água da bacia, com $50 \%$ da área irrigada correspondendo aos grandes perímetros irrigados do Departamento Nacional de Obras contra as Secas (Dnocs). A outra metada fica a cargo dos irrigantes particulares.

Os beneficiários desses recursos hídricos representam aproximadamente $35 \%$ da população total do estado, havendo maior concentração nas regiões do Cariri, Iguatu e Limoeiro do Norte.

A bacia do Jaguaribe, conforme definida, envolve as bacias do Alto, Médio e Baixo Jaguaribe, Salgado e Banabuiú; abrange quase metade da superfície do estado; acumula a maior quantidade de água (12,48 bilhões de $\left.^{3}\right)$; abriga os grandes açudes do estado do Ceará: Castanhão (6,7 bilhões de $\left.\mathrm{m}^{3}\right)$, Orós (1,94 bilhão de $\left.\mathrm{m}^{3}\right)$, Banabuiú (1,6 bilhão de $\left.\mathrm{m}^{3}\right)$ e Pedra Branca (434 milhões de $\left.\mathrm{m}^{3}\right)$, além de outros menores.

\subsection{Coleta de dados}

O período de estudo corresponde a 2005, ano em que o estado do Ceará registrou volume pluviométrico de $508,8 \mathrm{~mm}$, abaixo da média histórica (716,7 mm). No entanto, esses valores não são determinantes para inviabilizar ou distorcer os resultados da pesquisa, tendo em vista que em 2004 as precipitações ficaram muito acima da média, com elevada recarga dos mananciais, além do fato de a pesquisa estar voltada somente para atividades (culturas e pastagens para criações) irrigadas.

De acordo com dados da Cogerh, foram cadastrados 6.383 usuários de água bruta para fins de irrigação. A distribuição dos usuários por sub-bacia e por município foi dividida da seguinte maneira:

a) $34,3 \%$ dos irrigantes estão situados na sub-bacia do Baixo Jaguaribe, incluindo os irrigantes do perímetro irrigado de Morada Nova dentre os usuários de Limoeiro do Norte; e

b) $28,6 \%$ encontram-se na região do Alto Jaguaribe, $23,3 \%$ no Médio Jaguaribe e 13,7\% na sub-bacia do Banabuiú.

Foi feita também a distribuição dos usuários por estrato de área e a distribuição das áreas por município. 
Ressalta-se que, no presente estudo, considera-se para análise a área física da propriedade, já que os pontos referentes às áreas irrigadas por propriedade não são consistentes no banco de dados disponível. Essas informações serão analisadas somente a partir dos dados referentes à outorga.

Dos pontos em discussão, pode-se destacar:

a) $20,23 \%$ das propriedades cadastradas possuem área inferior ou igual a um hectare (ha);

b) 59,86\% das propriedades apresentam área entre 1 e 5 ha;

c) as propriedades com área superior a 50 ha não chegam a representar $1 \%$ do total cadastrado;

d) no que se refere à distribuição das áreas por sub-bacia, observa-se uma distribuição quase equitativa, ou seja, 28,97\% para a sub-bacia do Baixo Jaguaribe; $28,96 \%$ para a sub-bacia do Alto Jaguaribe; $20,89 \%$ para a subbacia do Banabuiu; e 19,76 para a bacia do Médio Jaguaribe;

e) o município que apresenta maior percentual de área é Morada Nova, com $20,8 \%$, seguido por Icó, com 17,96\% e Limoeiro do Norte com $15,64 \%$;

f) de acordo com os dados referentes à atualização do cadastro, mediante a solicitação ou renovação da outorga, na área de estudo têm-se 2.513 irrigantes, 33 carcinicultores e 3 piscicultores.

Para determinar o tamanho da amostra, utiliza-se o processo de amostragem probabilística do tipo aleatório simples proposto por Cochran (1977), ou seja:

$$
\mathrm{n}=\frac{\mathrm{Npq}}{(\mathrm{N}-1)\left(\frac{\mathrm{d}^{2}}{\mathrm{z}^{2}}\right)+\mathrm{pq}}
$$

em que:

$\mathrm{n}$ = tamanho da amostra que se deseja estimar;

$\mathrm{N}$ = Tamanho da população, expresso pelo número de irrigantes que solicitaram outorga de água à Cogerh;

$\mathrm{p}=\mathrm{q}=0,5$, proporções com as quais se obtém um " $\mathrm{n}$ " máximo;

$\mathrm{d}=$ desvio máximo do estimador médio em relação ao verdadeiro parâmetro (erro de amostragem), 10\%;

$\mathrm{z}=$ valor tabelado da distribuição normal no nível de significância de 5\%.

Desta forma, considerando-se um erro de amostragem de no máximo 10\%, um nível de significância de $5 \%(\alpha=0,05)$ e a população de irrigantes que solicitaram outorga de água à Cogerh, estimada em 2.513 irrigantes, conforme dados da Cogerh, estima-se o tamanho da amostra em 93 (Tabela 1).

A distribuição do número amostral entre os irrigantes dos perímetros públicos (Morada Nova, Icó/Lima Campos e Jaguaribe/Apodi) e os irrigantes privados dos municípios de São João do Jaguaribe, Icó, Tabuleiro, Limoeiro do Norte, Morada Nova, Banabuiu, Russas e Jaguaruana foi proporcional ao número de irrigantes das respectivas localidades. Durante a pesquisa, no 
entanto, para maior segurança e flexibilidade quando da análise crítica dos dados, foram entrevistados mais irrigantes que o número definido na amostra.

Após a definição do tamanho da amostra e contando com o apoio financeiro do $\mathrm{CNPq}$, foram elaborados questionários, aplicados em campo junto aos produtores irrigantes, que contemplaram receitas e custos (mão de obra, insumos e serviços, remuneração do empresário, capital utilizado na produção) das mais diversas atividades desenvolvidas pelos produtores, a exemplo de milho, feijão, melão, melancia, banana, goiaba, manga, criação de bovinos, entre outras.

Tabela 1. Plano amostral dos irrigantes públicos e privados da bacia do Jaguaribe, segundo informações da Cogerh, relativo ao ano de 2005.

\begin{tabular}{|c|c|c|c|c|c|}
\hline \multirow{2}{*}{ Discriminação } & \multirow{2}{*}{$\begin{array}{c}\text { Dados da } \\
\text { Amostra }\end{array}$} & \multirow{2}{*}{$\begin{array}{c}\text { Tipo de Irrigante/ } \\
\text { Município }\end{array}$} & \multirow{2}{*}{$\begin{array}{c}\text { Número de } \\
\text { Usuários }\end{array}$} & \multicolumn{2}{|c|}{ Amostra } \\
\hline & & & & Prevista & Aprovada \\
\hline & & Público & 1.532 & 56 & 66 \\
\hline Pop $(N)$, irrigantes & 2.513 & Morada Nova & 785 & 29 & 33 \\
\hline Proporção (p) & 0,5 & Icó Lima Campos & 534 & 20 & 20 \\
\hline Proporção (q) & 0,5 & Jaguaribe-Apodi & 213 & 8 & 13 \\
\hline $\operatorname{Desvio}(\mathrm{d})$ & 0,1 & & & & \\
\hline Nível de Confiança (z) & 1,96 & & & & \\
\hline Tamanho da Amostra & 93 & Privado & 981 & 36 & 37 \\
\hline & & S. J. Jaguaribe/Icó & 290 & 10 & 11 \\
\hline & & Limoeiro & 342 & 13 & 13 \\
\hline & & Morada Nova/Banabuiú & 162 & 6 & 6 \\
\hline & & Russas/Jaguaruana & 187 & 7 & 7 \\
\hline & & Total & 2.513 & 93 & 103 \\
\hline
\end{tabular}

Fonte: Dados da pesquisa.

\subsection{Métodos de Análises}

Neste estudo consideram-se os fatores de risco no cálculo da capacidade de pagamento do irrigante usuário de água bruta da bacia do Jaguaribe, Ceará.

\subsubsection{Método Residual}

\subsubsection{Capacidade de Pagamento Total}

Inicialmente, chama-se a atenção de que todas as receitas e custos referemse exclusivamente às atividades produtivas que usam água como insumo básico para irrigação.

Assim, como componentes das receitas não foram incluídos os ganhos de atividades extras e não irrigadas executadas pelo proprietário/empresário, tais como comércio, trabalho assalariado fora da propriedade e doações de familiares, nem custos particulares dele ou da família ou da residência (manutenção e 
aluguel da residência, energia residencial, despesas com veículo particular de uso próprio ou familiar, com vestuário, saúde, lazer, etc.).

Desta forma, a Receita Bruta (RB) é definida como o valor da produção total da empresa ou da atividade durante certo período contábil (um ano, no presente caso), quer seja a mesma vendida ou não. Assim sendo, compreende a produção oriunda das atividades irrigadas que foi vendida, usada para o consumo familiar, como semente ou ração para o gado, para pagamentos em espécie, doada a parentes e amigos ou que foi armazenada durante ou no final do período contábil, além do aluguel de animais, máquinas e equipamentos, entre outros.

Conceitualmente, todos os componentes da produção, inclusive os que não são vendidos, devem ser avaliados pelo preço de mercado. Em alguns casos, o cálculo é direto: simplesmente a quantidade produzida multiplicada pelo preço. Em outras situações, como nos casos de culturas perenes (a exemplo de banana, goiaba e manga) e rebanhos (bovino, caprino e ovino) que mudam de valor entre períodos contábeis, existe a necessidade de se fazer a devida avaliação durante o período contábil do estudo.

Para se estimar os custos das atividades ou empresa em análise, empregamse os conceitos de custo operacional e de custo total de produção (VARIAN, 1994; PINDYCK e RUBINFELD, 1994; MATSUNAGA, 1976; MARTIN, 1998).

Assim, o custo compõe-se de todos os custos variáveis (aqueles que variam em proporção mais ou menos direta com as quantidades produzidas), exceto o custo da água. Os custos variáveis são compostos pelos dispêndios em mão de obra temporária (diarista) contratada e familiar, exceto o empresário, serviços mecanizados e tração animal contratados, defensivos, adubos orgânico e químico, calcário, sementes, mudas, alimentação, sal mineral, vacinas, medicamentos, energia e outros.

Já os custos fixos anuais (que não variam com as quantidades produzidas) são representados pela depreciação dos bens duráveis (máquinas, equipamentos e benfeitorias) empregados nas atividades, depreciação de animais de serviços, de reprodutores e de matrizes comprados para melhoramento do rebanho, conservação de máquinas, equipamentos e benfeitorias, o valor da mão de obra permanente, inclusive a familiar, exceto o empresário, os impostos e as taxas que independem da produção e algumas despesas gerais que são comuns às atividades irrigadas e não irrigadas.

Neste último grupo, incluem-se, também, os juros (remuneração) sobre a terra própria, correspondendo ao custo de oportunidade de uso da terra; os juros sobre o capital alocado em máquinas, equipamentos, benfeitorias, animais, culturas permanentes e pastagens não anuais, representando o custo de oportunidade ou a melhor compensação que os donos dos fatores de produção devem receber para continuar empregando esses fatores em atividades produtivas; e a remuneração pelo trabalho executivo e administrativo do empresário ou proprietário, definida pelo custo de oportunidade ou a respectiva retribuição financeira que poderia ser obtida em outro (melhor) emprego alternativo. 
As despesas gerais citadas anteriormente devem ser rateadas proporcionalmente entre aquelas atividades, obedecendo ao melhor critério que, segundo Hoffmann et al. (1976), pode ser de acordo com a relação percentual de receita bruta entre as atividades, pela distribuição percentual dos custos específicos entre as várias atividades, além de proporcionalmente em relação à área e à quantidade de mão de obra usada em cada atividade.

No cálculo dos custos fixos podem-se usar os seguintes critérios técnicos:

i) Depreciação de máquinas e benfeitorias - considera-se para fins de cálculo de depreciação o valor atual ou de reposição e a respectiva vida útil futura dos bens de capital.

ii) Conservação e manutenção de máquinas, equipamentos e benfeitorias determina-se tomando por base a literatura especializada, sendo $2 \%$ ao ano para benfeitorias e $3 \%$ para máquinas e equipamentos.

iii) Juros (remuneração) sobre o capital - avalia-se o valor dos bens de capital compostos por máquinas, equipamentos, benfeitorias, terra, culturas perenes, pastagens não anuais e capital de giro. Em seguida, aplicase sobre aquele valor uma taxa real de juros de 6\% ao ano. Esta taxa é estimada com base no retorno alternativo e aproximado da poupança no mercado de capitais, na inflação observada durante o ano do estudo e no fato de que os investimentos na agricultura têm pequena liquidez.

iv) Renda ou remuneração do empresário - estima-se como a remuneração (ganho) média alternativa possível de obter pelos serviços de empresário ou de produtor em emprego alternativo.

A partir dos resultados anteriores, calcula-se a capacidade de pagamento (CP) do produtor em relação a um dado fator, usando-se o método residual. Segundo Agüero (1996) e Bate e Dubourg (1997), este método permite determinar o valor do recurso hídrico por meio de análise e desagregação de orçamentos das unidades produtivas (irrigantes). Assim, este método consiste em se subtrair da receita bruta total obtida a remuneração de todos os fatores de produção empregados na(s) atividade(s), exceto o recurso água, encontrando-se um resíduo (net-back) que refletirá a capacidade de poupança gerada pelo produtor para fazer face ao uso da água como fator de produção. Matematicamente, tem-se:

$$
\mathrm{CPT}=\left(\mathrm{P}_{\mathrm{y}} * \mathrm{Y}\right)-\mathrm{CT}
$$

$\mathrm{ou}$

$$
\mathrm{CPT}=\mathrm{RBT}-\mathrm{CT}
$$

em que:

$\mathrm{CPT}=$ Capacidade de pagamento total pelo fator água ou renda líquida residual; $\mathrm{P}_{\mathrm{y}}=$ Preço ao produtor dos produtos da empresa;

$\mathrm{Y}=$ a quantidade produzida pela empresa; 
RBT = Receita bruta total das atividades que usam a água como fator de produção (no caso, culturas irrigadas);

$\mathrm{CT}=$ Custo total (fixos e variáveis), exceto o custo do fator água.

\subsubsection{Capacidade de Pagamento Unitária}

Finalmente, é possível estimar a capacidade de pagamento unitária, isto é, por unidade do fator, matematicamente, estimada como:

$$
\mathrm{CP}_{\mathrm{U}}=\mathrm{CPT} / \mathrm{V}
$$

em que:

$\mathrm{CP}_{\mathrm{U}}=$ Capacidade de pagamento unitária, em $\left(\mathrm{R} \$ / 1000 \mathrm{~m}^{3}\right)$;

$\mathrm{CPT}=$ Capacidade de pagamento total pelo fator água, em reais;

$\mathrm{V}=$ Volume de água consumido $\left(\mathrm{em}_{\left.1000 \mathrm{~m}^{3}\right)}\right.$ durante o período contábil.

O volume de água consumido durante o período em foco foi levantado junto à Cogerh, considerando o tipo de cultura, o período anual de irrigação, a localidade (Russas, Limoeiro, S. João do Jaguaribe, etc.), a área cultivada e o tipo de irrigação empregado em cada cultura.

\subsubsection{O método de simulação Monte Carlo}

Em síntese, o método de simulação Monte Carlo pode ser descrito em quatro etapas principais, que são:

i) Identificar a distribuição de probabilidade de cada variável ou parâmetro relevante para a tomada de decisão do produtor. A análise de investimento de um projeto envolve grande número de variáveis que compõem os fluxos de benefícios e os fluxos de custos, como quantidade e preços de produtos, serviços e insumos e produtividade das explorações que, em geral, têm comportamentos aleatórios e atuam de forma diferenciada na determinação dos indicadores de rentabilidade, sendo que algumas representam maior importância, em termos quantitativos, enquanto outras atuam com menor impacto. Deve-se, portanto, considerar como aleatórias apenas aquelas de maior importância (doravante denominada de relevantes) e as demais como deterministas, ou seja, de valor constante. Diante desta recomendação, efetuou-se a análise de sensibilidade nesta determinação.

ii) Simularvalores aleatórios decada variávelou parâmetroem análise. Nesta etapa, são simulados ou gerados, através da utilização de computador, os valores aleatórios para cada variável eleita como relevante na etapa anterior, a partir das distribuições de probabilidades identificadas. Nesta etapa, bem como nas seguintes, será utilizado o software ALEAXPRJ, desenvolvido por Azevedo Filho (1988). O ALEAXPRJ é um sistema para simulação e análise de projetos envolvendo risco. 
iii) Para cada valor aleatório selecionado no item (ii), calcula-se o indicador de rentabilidade correspondente, que pode ser a Margem Bruta (MB), a Relação Benefício-Custo (RBC), a capacidade de pagamento (CP), ou qualquer outro.

iv) Repetir o processo por um número suficiente de vezes, (de 4000 a 5000 vezes), de forma a se obter a configuração da distribuição de probabilidade dos indicadores de rentabilidade selecionados. É com base nesta distribuição que será tomada a decisão. Noronha (1981, p. 248) sugere repetir os dois passos anteriores entre 200 e 300 vezes, mas admite que este procedimento "pode ser tão alto quanto os custos de computação permitirem" (sic).

Assim sendo, o cálculo da capacidade de pagamento, ao invés do enfoque determinista comumente usado, é agora feito considerando-se a probabilidade ou possibilidade de pagamento do irrigante, ou seja, sob condições de risco.

No presente caso, tanto as receitas como os custos, assim como o volume de água bruta utilizada $\left(\mathrm{em} 1000 \mathrm{~m}^{3}\right)$, foram calculados por hectare. Portanto, a capacidade de pagamento total (CPT) é definida por hectare, ocorrendo o mesmo para a capacidade de pagamento unitária $\left(\mathrm{CP}_{\mathrm{u}}\right)$.

Neste estudo, foram estimadas distribuições de probabilidade empíricas para a receita bruta e para os custos com mão de obra, insumos e serviços, remuneração do empresário, depreciação, conservação e remuneração (juros) do capital (Apêndice A).

\section{Resultados e Discussão}

Na Tabela 2 apresentam-se os indicadores estimados, por meio de 4000 simulações, para avaliação da CP dos irrigantes privados, desmembrados em subgrupos de atividades, e públicos, por atividade principal e por perímetro. Verifica-se que a CP por hectare, calculada para todos os irrigantes privados da amostra (37 irrigantes), apresentou valor médio negativo de $R \$ 51,71$ por $1000 \mathrm{~m}^{3}$, significando que a maioria desses produtores não tem condição de pagar pelo uso da água, ou melhor, após todas as simulações ficou evidenciado que apenas $33,2 \%$ é a probabilidade de a capacidade de pagamento ser positiva, $\mathrm{P}(\mathrm{CP}>\mathrm{L})$ $=33,2 \%$, sendo $\mathrm{L}=0,00$ (limite mínimo estabelecido para a $\mathrm{CP}$ ). Quando $\mathrm{CP}>$ $\mathrm{L}$ significa que todos os custos foram remunerados e sobrou um resíduo para pagamento de água para irrigação. No caso de $\mathrm{CP}=0$ indica que não há sobra de dinheiro para pagar o fator água. Ainda o irrigante privado, aquele que tem a pecuária como atividade principal, é quem apresenta melhor resultado, mesmo assim sujeito a fatores de risco elevado, pois somente $32,4 \%$ é a probabilidade de a $\mathrm{CP}$ ser positiva e, em média, a $\mathrm{CP}$ por hectare desse subgrupo é negativa, da ordem de $\mathrm{R} \$ 53,67$ por $1000 \mathrm{~m}^{3}$. Em ordem decrescente vêm os subgrupos de produtores de grãos $(16,9 \%)$ e dos fruticultores $(4,8 \%)$. 
372 - Avaliação Sob Risco da Capacidade de Pagamento por Água Bruta de Produtores da Bacia do Jaguaribe (CE)

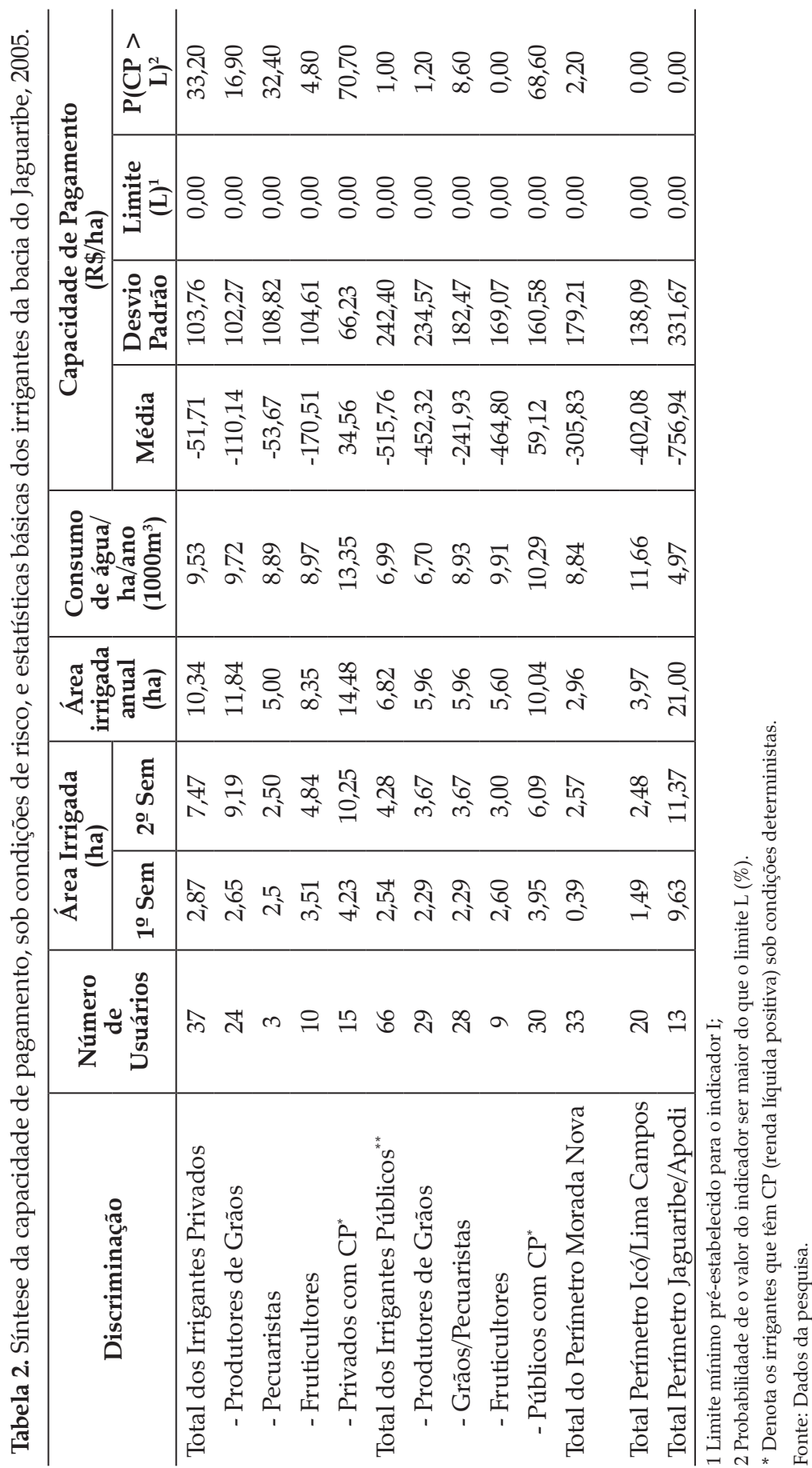


Quando se faz a separação, para fins de cálculo do Monte Carlo, entre os irrigantes que têm $\mathrm{CP}$ positiva sob condições deterministas, ou seja, com renda líquida maior do que zero, daqueles que apresentaram renda líquida negativa, os primeiros, em número de 15 (40,54\% dos irrigantes privados), mostram que, em média, podem pagar por hectare até $\mathrm{R} \$ 34,56$, assumindo a probabilidade de $70,7 \%$ de a CP ser positiva, portanto, de baixo risco.

O governo do estado do Ceará por meio do decreto no 27.271, de 28 de novembro de 2003, Art. $3^{\text {o }}$ regulamenta no item VI o valor da tarifa para água bruta para fins de irrigação. Estabelece que a cobrança seja da forma monomial, que admite tarifa apenas definida com base na água consumida (tarifa de consumo). Desta forma, segundo o decreto, produtores irrigantes com consumo de $12.000 \mathrm{~m}^{3} / \mathrm{mês}$ até $18.999 \mathrm{~m}^{3} / \mathrm{mês}$ devem pagar uma tarifa de $\mathrm{R} \$ 6,50 / 1.000 \mathrm{~m}^{3}$.

Considerando-se que os irrigantes privados com CP consomem, em média, $193.308 \mathrm{~m}^{3}$ de água por ano, ou seja, $16.109 \mathrm{~m}^{3}$ por mês, suas CPs anuais seriam de $\mathrm{R} \$ 500,00$ contra $\mathrm{R} \$ 1.256,00$ de tarifa volumétrica anual cobrada atualmente pela Cogerh. Portanto, embora esses irrigantes apresentem CP por hectare com baixo risco, o resíduo ou renda disponível não é suficiente para cobrir a tarifa.

Analisando-se o irrigante público, constata-se que em termos de valores médios, a CP é negativa para o total dos produtores da bacia do Jaguaribe e a probabilidade é de apenas $1 \%$ de a $\mathrm{CP}$ ser positiva, com risco absoluto. A mais alta probabilidade de $\mathrm{CP}$ desse grupo fica por conta do subgrupo que tem como atividades principais a produção de grãos/pecuária $(8,6 \%)$, seguindo-se dos produtores de grãos $(1,2 \%)$ e dos fruticultores $(0 \%)$ sem nenhuma probabilidade de $\mathrm{CP}$, definindo risco absoluto ou extremo.

Dos 66 irrigantes públicos que compõem a amostra, 30 deles $(45,45 \%)$ apresentaram $\mathrm{CP}$ pelo fator água positiva, sob condições deterministas. Os valores dos parâmetros e variáveis relativos a esses produtores foram isolados e submetidos a teste por meio do método Monte Carlo, encontrando-se, em média, uma CP por hectare de $\mathrm{R} \$$ 59,12 para um volume médio anual de água consumida de $103.311,60 \mathrm{~m}^{3}$, ou seja, $8.609 \mathrm{~m}^{3}$ por mês, sendo de $68,6 \%$ a probabilidade de os irrigantes apresentarem $\mathrm{CP}$ positiva; portanto, de risco baixo.

Os irrigantes públicos com CP consomem, em média, $103.311,60 \mathrm{~m}^{3}$ de água por ano e suas CPs anuais são de $\mathrm{R} \$ 593,60$ contra $\mathrm{R} \$ 578,40$ de tarifa anual cobrada atualmente pela Cogerh, portanto, situando-se numa situação confortável.

Quando se efetua a análise do irrigante público, por perímetro, verifica-se que, em termos de valores médios, a $\mathrm{CP}$ é negativa para todos. O risco de não ter CP pela água é significativo, ou seja, chega a ser de $100 \%$ para os perímetros de Icó/Lima Campos e DIJA e de 2,2\% para Morada Nova.

Por fim, chama-se a atenção de que todas as distribuições que proporcionaram o uso do método Monte Carlo encontram-se relacionadas nas Tabelas A.1 a A.4 do Apêndice. As distribuições de probabilidades foram definidas por meio dos dados levantados junto aos produtores e discussão com técnicos ou especialistas 
que trabalham nos perímetros. Um exemplo de modelo de programa, formulado pelo autor deste trabalho para o cálculo da $\mathrm{CP}$ dos irrigantes privados, é também disponibilizado no mesmo Apêndice. Para o irrigante público foi usado também o mesmo programa, efetuando-se as modificações dos parâmetros/variáveis pertinentes.

Apesar de o método Monte Carlo avançar significativamente em relação aos procedimentos deterministas, ainda permanecem algumas limitações, tendo em vista que a análise de sensibilidade, empregada para selecionar variáveis aleatórias importantes, não resolve os problemas de análise de risco satisfatoriamente, em razão de ela levar em conta apenas uma variável de cada vez. Outra limitação do método Monte Carlo consiste em até onde agregar ou desagregar as variáveis sem perder de vista o grau de correlação entre elas.

\section{Conclusões}

Da análise da capacidade de pagamento, sob condições de risco, efetuada por meio do método Monte Carlo, conclui-se que para os irrigantes privados da amostra, a capacidade de pagamento por água bruta apresenta valor médio negativo de R \$51,71 por hectare. Este resultado demonstra que a maioria desses produtores não tem condição de pagar pelo uso da água, ou melhor, após todas as simulações ficou evidenciado que apenas $33,2 \%$ é a probabilidade de a capacidade de pagamento ser positiva, portanto de risco elevado.

Ainda para o irrigante privado, aquele que tem a pecuária como atividade principal é quem apresenta melhor resultado, mesmo assim sujeito a risco elevado, pois somente $32,4 \%$ é a probabilidade de a capacidade de pagamento ser positiva e, em média, a capacidade de pagamento desse subgrupo é negativa, da ordem de $\mathrm{R} \$ 53,67$ por hectare.

Quando se faz a simulação Monte Carlo somente para os irrigantes privados e públicos que têm capacidade de pagamento positiva, sob condições deterministas, ou seja, com renda líquida (residual ou net-back) maior do que zero, conclui-se que, em média, apenas os irrigantes públicos podem pagar com sobra de caixa ou baixo risco o valor da tarifa atualmente cobrada pela Cogerh.

Para o irrigante público, conclui-se que em termos de valores médios a capacidade de pagamento é negativa para o total dos produtores da bacia do Jaguaribe e a probabilidade é de apenas $1 \%$ de a capacidade de pagamento ser positiva, com risco absoluto. A mais alta probabilidade de capacidade de pagamento desse grupo fica por conta do subgrupo que tem como atividades principais a produção de grãos/pecuária $(8,6 \%)$, seguindo-se dos produtores de grãos $(1,2 \%)$ e dos fruticultores $(0 \%)$ sem nenhuma probabilidade de capacidade de pagamento, definindo risco absoluto ou extremo.

Quando se efetua a análise do irrigante público, por perímetro, conclui-se que, em termos de valores médios, a capacidade de pagamento é negativa 
para todos. O risco de não ter capacidade de pagamento da tarifa cobrada pela água é significativo, ou seja, chega a ser de $100 \%$ para os perímetros de Icó/Lima Campos e Jaguaribe/Apodi (DIJA) e de 97,8\% para Morada Nova.

Em conclusão final da avaliação sob condições de risco, tem-se que, regra geral, para aqueles irrigantes que apresentaram capacidade de pagamento, os públicos mostraram-se melhor do que os privados.

Parte das limitações deste estudo foi eliminada com a análise de sensibilidade, mas este procedimento não resolve os problemas de análise de risco satisfatoriamente, em razão de ela levar em conta apenas uma variável de cada vez; resulta que os efeitos negativos de uma variável podem ser compensados pelos efeitos positivos de outra, além de não detectar falhas nas estimativas dos valores iniciais das variáveis. Outra limitação do método Monte Carlo consiste em até onde agregar ou desagregar as variáveis sem perder de vista o grau de correlação entre elas. Apesar de tudo isso, sabe-se que os riscos continuam existindo, mas o irrigante dispõe de informação mais completa em sua tomada de decisão sobre o que, como e quanto produzir.

\section{Referências Bibliográficas}

AGÜERO, P. H. Avaliação econômica dos recursos naturais. 1996. 224f. Tese (Doutorado em Economia) - Universidade de São Paulo, São Paulo, 1996.

ALVES, E. Modelos institucionais de irrigação. Brasília: Ministério da Irrigação/ CODEVASF, 1988. 15p.

ARROJO AGUDO, P.; MÍGUELEZ, E. Y BARAKAT, M. Análisis y valoración socioeconómica de los trasvases del ebro previstos en el phn. Facultad de Ciencias Económicas y Empresariales Universidad de Zaragoza. 2002. Disponível em <http:/assets. wwfes.panda.org/downloads/resumen_estudio_socioeconomico.pdf $>$. Acesso em 24 abr. 2009.

ASSIRAT, E. B. Uma avaliação das políticas de irrigação no Nordeste. Revista Econômica do Nordeste, Fortaleza, v. 25, n. 4, p. 545-574, 1994.

AZEVEDO FILHO, A.J.B.V. ALEAXPRJ - Sistema para simulação e análise econômica de projetos em condições de risco. Piracicaba: USP, 1988. 158p.

BATE, R.N.; DUBOURG, W.R. A net-back analysis of irrigation water demand in east Anglia. Journal of Environmental Management, London, v. 49, p. 311-322, 1997.

BISERRA, J.V. Rentabilidade da irrigação pública no Nordeste sob condições de risco: o caso do perímetro de Morada Nova. 1991. 73f. Tese (Professor Titular)-Departamento de Economia Agrícola, Universidade Federal do Ceará, Fortaleza, 1991. 
BRASIL. Lei no 6.662, de 25 de junho de 1979. Dispõe sobre a Política Nacional de Irrigação e dá outras providências. Diário Oficial da República Federativa do Brasil, Brasília, DF, 26jun. 1979. Disponível em: http://www.planalto.gov.br/ Ccivil_03/LEIS/L6662.htm. Acesso em: 03jun. 2008.

CAMPOS, R.T. Efeitos do ataque do bicudo na cotonicultura do semi-árido cearense. 1991. 160f. Tese (Doutorado em Economia) - PIMES, Universidade Federal de Pernambuco, Recife, 1991.

CAMPOS, N.; STUDART, T. M. de C. Gestão da demanda. In: CAMPOS, N.; STUDART, T. M. de C (org.). Gestão de águas: princípios e práticas. Porto Alegre: ABRH, 2001. p. 63-80.

CLINE, W. R. Análise de custo-benefício de projetos de irrigação no Nordeste. Pesquisa e Planejamento Econômico, Rio de Janeiro, v. 2, n. 2, p. 257-274, dez. 1972.

COCHRAN, W.G. Técnicas de amostragem. Rio de Janeiro: Fundo de Cultura, 1977.

GARRIDO, A. C. La importancia del valor, costo y precio de los recursos hídricos em su gestión. Editora Biblioteca Virtual Proyecto FODEPAL. 2004. Disponível em < http://www.fodepal.es/Bibvirtual/PAP/papelesnew\%20pdf/palaciosgarridonew. pdf $>$. Acesso em 23 jun. 2009.

HOFFMANN, R. et al. Administração da empresa agrícola. 5 ed., São Paulo: Pioneira, 1987. 325p.

FERREIRA, A. M. R., Análise da disposição a pagar pela preservação do manguezal do Rio Ceará. 1998.111f. Dissertação (Mestrado em Desenvolvimento e Meio Ambiente) - Departamento de Economia Agrícola, Universidade Federal do Ceará, Fortaleza, 1998.

KEMPER, K.E.; OLSON, D. Water pricing: the dynamics of institutional change in Mexico and Ceará, Brazil. In: DINAR, A. (org.). The Political Economy of Water Pricing Reforms. Washington: World Bank/ Oxford University, 1998. p. 339-357.

MATSUNAGA, M. et alii. Metodologia de custo de produção utilizada pelo IEA. Agricultura em São Paulo, São Paulo, v. 13, p. 123-39, 1976.

MARTIN, N.B. et alii. Sistema integrado de custos agropecuários. CUSTAGRI. Informações Econômicas, São Paulo, v. 28, n. 1, p. 7-28, jan. 1998.

NORONHA, J. F. de. Projetos agropecuários: administração financeira, orçamentação e avaliação econômica. São Paulo: Fundação de Estudos Agrários Luiz de Queiroz, 1981. 274p.

PEREIRA NETO, A. Tarifa dágua e viabilidade de projetos públicos de irrigação. 1998. 143f. Dissertação (Mestrado em Economia Rural) - Universidade Federal de Viçosa, Minas Gerais, 1998. 
PINHEIRO, J. C. V.; LIMA, A. T. de M. Valor econômico da água para irrigação: uma aplicação do método residual. In: III ENCUENTRO DE LAS AGUAS, 3., 2001, Santiago. Anais... Santiago de Chile, Instituto Interamericano de Cooperación para la Agricultura (IICA), 2001. Disponível em: <http://www.bvsde.paho.org/ bvsacd/encuen/melo>. Acesso em: 23 mar. 2008.

PINHEIRO, J. C. V.; LIMA, A. T. de M. Valor econômico e elasticidade preço da demanda de água para irrigação no vale do Apodi-Ce. In: ROSA, Antônio Lisboa Teles da; KHAN, Ahmad Saeed (org). Nordeste: reflexões sobre aspectos setoriais e locais de uma economia. 1aed. Fortaleza: CAEN, 2002, p. 293-308.

PINDYCK, R.S.; RUBINFELD, D.L. Microeconomia. São Paulo: Makron Books, 1994. 968p.

SECRETARIA DOS RECURSOS HÍDRICOS DO ESTADO DO CEARÁ. Caracterização da área e identificação dos usuários de água bruta nos vales dos Rios Jaguaribe e Banabuiú. Fortaleza: Tahal - Consulting Engineers Ltda., JP Brasil e PROGERIRH. Maio de 2002.

VARIAN, H. R. Microeconomia: princípios básicos. $2^{\underline{a}}$ ed. Rio de Janeiro: Campus, 1994. 710p.

VIEIRA, V. Análise de risco. In: CAMPOS, N.; STUDART, T. M. de C (org.). Gestão de águas: princípios e práticas. Porto Alegre: ABRH, 2001. p. 129-138. 
378 - Avaliação Sob Risco da Capacidade de Pagamento por Água Bruta de Produtores da Bacia do Jaguaribe (CE)

\section{Apêndice}

Tabela A.1. Distribuições de probabilidades das receitas e custos por hectare para os irrigantes privados totais da bacia do Jaguaribe, 2005.

\begin{tabular}{l|r|r|r|r|r|r|r}
\hline & \multicolumn{1}{|c|}{$\begin{array}{c}\text { Receita } \\
\text { Total }\end{array}$} & $\begin{array}{c}\text { Custo } \\
\text { da Mão } \\
\text { de Obra } \\
\text { Total }\end{array}$ & $\begin{array}{c}\text { Custos } \\
\text { insumos e } \\
\text { serviços }\end{array}$ & $\begin{array}{c}\text { Remune- } \\
\text { ração do } \\
\text { Empresário }\end{array}$ & Depreciação & $\begin{array}{c}\text { Custo } \\
\text { Manutenção }\end{array}$ & $\begin{array}{l}\text { Custo } \\
\text { Juros }\end{array}$ \\
\hline Média & 4503,49 & 884,39 & 1307,70 & 1107,16 & 355,48 & 93,77 & 276,57 \\
Máximo & 13213,47 & 3021,75 & 3482,13 & 2864,60 & 1788,55 & 440,68 & 810,27 \\
Mínimo & 981,64 & 58,30 & 302,17 & 193,82 & 35,25 & 8,92 & 57,52 \\
\hline
\end{tabular}

Fonte: Dados da pesquisa.

Tabela A.2. Distribuições de probabilidades das receitas e custos por hectare para os irrigantes privados com capacidade de pagamento, sob condições deterministas, da bacia do Jaguaribe, 2005.

\begin{tabular}{l|r|r|r|r|r|r|r}
\hline & \multicolumn{1}{|c|}{$\begin{array}{c}\text { Receita } \\
\text { Total }\end{array}$} & $\begin{array}{c}\text { Custo } \\
\text { Mão de } \\
\text { Obra Total }\end{array}$ & $\begin{array}{c}\text { Custos } \\
\text { insumos e } \\
\text { serviços }\end{array}$ & $\begin{array}{c}\text { Remune- } \\
\text { ração do } \\
\text { Empresário }\end{array}$ & $\begin{array}{c}\text { Custo } \\
\text { Depreciação }\end{array}$ & $\begin{array}{c}\text { Custo } \\
\text { Manutenção }\end{array}$ & $\begin{array}{l}\text { Custo } \\
\text { Juros }\end{array}$ \\
\hline Média & 6941,21 & 1139,46 & 1656,72 & 1027,36 & 246,02 & 67,17 & 403,54 \\
Máximo & 13213,47 & 3021,75 & 2998,61 & 2017,68 & 576,14 & 177,58 & 810,27 \\
Mínimo & 2746,04 & 107,67 & 675,75 & 267,92 & 47,20 & 10,39 & 134,78 \\
\hline
\end{tabular}

Fonte: Dados da pesquisa.

Tabela A.3. Distribuições de probabilidades das receitas e custos por hectare para os irrigantes públicos totais da bacia do Jaguaribe, 2005.

\begin{tabular}{l|r|r|r|r|r|r|r}
\hline & \multicolumn{1}{|c|}{$\begin{array}{c}\text { Receita } \\
\text { Total }\end{array}$} & $\begin{array}{c}\text { Custo } \\
\text { Mão de } \\
\text { Obra Total }\end{array}$ & $\begin{array}{c}\text { Custos } \\
\text { insumos e } \\
\text { serviços }\end{array}$ & $\begin{array}{c}\text { Remune- } \\
\text { ração do } \\
\text { Empresário }\end{array}$ & $\begin{array}{c}\text { Custo } \\
\text { Depreciação }\end{array}$ & $\begin{array}{c}\text { Custo } \\
\text { Manutenção }\end{array}$ & $\begin{array}{l}\text { Custo } \\
\text { Juros }\end{array}$ \\
\hline Média & 4541,57 & 1042,21 & 1420,70 & 1659,28 & 332,93 & 89,56 & 750,42 \\
Máximo & 15692,24 & 4420,95 & 5932,06 & 4355,62 & 1417,88 & 347,93 & 2494,26 \\
Mínimo & 997,80 & 125,73 & 180,73 & 182,09 & 6,86 & 1,19 & 87,29 \\
\hline
\end{tabular}

Fonte: Dados da pesquisa.

Tabela A.4. Distribuições de probabilidades das receitas e custos por hectare para os irrigantes públicos com capacidade de pagamento, sob condições deterministas, da bacia do Jaguaribe, 2005.

\begin{tabular}{l|r|r|r|r|r|r|r}
\hline & \multicolumn{1}{|c|}{$\begin{array}{c}\text { Receita } \\
\text { Total }\end{array}$} & $\begin{array}{c}\text { Custo } \\
\text { Mão de } \\
\text { Obra Total }\end{array}$ & $\begin{array}{c}\text { Custos } \\
\text { insumos e } \\
\text { serviços }\end{array}$ & $\begin{array}{c}\text { Remune- } \\
\text { ração do } \\
\text { Empresário }\end{array}$ & $\begin{array}{c}\text { Custo } \\
\text { Depreciação }\end{array}$ & $\begin{array}{c}\text { Custo } \\
\text { Manutenção }\end{array}$ & $\begin{array}{l}\text { Custo } \\
\text { Juros }\end{array}$ \\
\hline Média & 6075,18 & 964,63 & 1607,55 & 1194,20 & 224,72 & 57,27 & 627,06 \\
Máximo & 15692,24 & 3479,92 & 4485,35 & 3246,55 & 596,60 & 129,50 & 1356,20 \\
Mínimo & 2308,19 & 127,40 & 297,71 & 258,31 & 17,66 & 3,21 & 155,57 \\
\hline
\end{tabular}

Fonte: Dados da pesquisa. 


\section{ARQUIVO-PROGRAMA DO ALEAXPRJ}

USP/CIAGRI/ALEAXPRJ - Simulação e Analise Econômica de Projetos Envolvendo Risco

Projeto: CAPAC. DE PAGAM. DOS IRRIGANTES DO BAIXO JAGUARIBE

*** Listagem do Arquivo MC_PRIV.PRJ

1 | ANALISE:CAPAC. DE PAGAM. DOS IRRIGANTES DO BAIXO JAGUARIBE - IRRIGANTES PRIVADOS;

2 | ANALISTA:PESQUISADOR;

3 | SIMULACOES:4000;

4 | CO:0.06;

5 | PERIODOS:0;

6 | DATA:20/01/07;

7 | IMPRIME_PROG:LIGADO;

8 | VARIAVEIS EXOGENAS TEMPORAIS

9 | RT:TRIANGULAR[4503.49,981.64,13213.47],

10 | MO:TRIANGULAR[884.39,58.30,3021.75],

11 | CT:TRIANGULAR[1307.70,302.17,3482.13],

12 | RE:TRIANGULAR[1107.16,193.82,2864.60],

13 | DE:TRIANGULAR[355.48,35.25,1788.55],

14 | MA:TRIANGULAR[93.77,8.92,440.68],

15 | JU:TRIANGULAR[276.57,57.52,810.27],

16 | AG:SPIKE[9.53];

17 | VARIAVEIS EXOGENAS CONSTANTES;

18 | VARIAVEIS ENDOGENAS TEMPORAIS;

19 | VARIAVEIS ENDOGENAS CONSTANTES

20 | REC,

21 CUST,

22 | CPT,

23 | CPM;

24 | RESULTADOS[CPT:2:0,CPM:2:0];

$25 \mid\{$

26 | REC:=RT[0];

27 | CUST:=MO[0]+CT[0]+RE[0]+DE[0]+MA[0]+JU[0];

28 | CPT:=REC-CUST;

29 | CPM:=CPT/AG[0];

30 | INDICADORES;

$31 \mid\}$. 
